\title{
BAL MUMUNUN YAPISI, KULLANIM ALANLARI ve BAZI TEMEL SORUNLARI
}

\author{
Structure, Usage Areas and Main Problems of Bees Wax
}

\author{
Erkan TOPAL ${ }^{1 *}$, Özgür CEYLAN ${ }^{2}$, Mustafa KÖSOĞLU ${ }^{3}$, Rodica MĂRGĂOAN $^{4}$, \\ Mihaiela CORNEA-CIPCIGAN ${ }^{5}$
}

\begin{abstract}
${ }^{1 *}$ Ege Tarımsal Araştırma Enstitüsü, Arıcılık Ar-Ge İnovasyon Merkezi, İzmir, TÜRKIYE, ORCID No: 0000-0002-13984390, Yazışma Yazarı: email: topalerkan@tarimorman.gov.tr

2Ula Ali Koçman Meslek Yüksekokulu, Gıda İşleme Bölümü, Gıda Kalite Kontrolü ve Analizi Programı, Muğla, TÜRKiYE, ORCID No: 0000-0002-1865-1093

${ }^{3}$ Ege Tarımsal Araştırma Enstitüsü, Arıcılık Ar-Ge İnovasyon Merkezi, İzmir, TÜRKIYE, ORCID No: 0000-0001-6616-089X

${ }^{4}$ University of Agricultural Sciences and Veterinary Medicine, Advanced Horticultural Research Institute of Transylvania, Department of Microbiology and Biotechnologies, Cluj-Napoca, ROMANIA, ORCID No: 0000-0002-9246-1677

${ }^{5}$ University of Agricultural Sciences and Veterinary Medicine, Faculty of Horticulture, Department of Horticulture and Landscaping, Cluj-Napoca, ROMANIA, ORCID No: 0000-0003-3313-2416
\end{abstract}

Geliş Tarihi / Received:16.08.2020

Kabul Tarihi / Accepted: 29.09.2020

DOI:10.31467/uluaricilik.781259

\section{ÖZ}

Bal mumu arı kolonisinin yaşamsal faaliyetlerini üzerinde yürüttüğü peteğin ham maddesidir. Arıcılık işletmeleri için bal, polen, arı sütü ve arı ekmeği gibi bal mumu da bir arı ürünüdür. Bal mumu absorbe etme yeteneği kaynaklı kovan içi ve dışı kirleticileri bünyesinde biriktirebilmektedir. Bu şekilde kalıntı içeren peteklerden üretilen arı ürünleri insan ve arı sağlığı için risk oluşturmaktadır. Aynı zamanda eski petekler patojen mikroorganizmalar için konak işlevi görebilmektedir. Özellikle petek işleme tesisleri eski peteklerin hijyenik hale gelmesi açısından oldukça önemli bir sorumluluk taşımaktadır. Bal mumunun çok geniş bir kullanım alanı içermesi dikkatleri de üzerine çekmiştir. Gıda sektöründe kaplayıcı ajan olarak, kozmetikte sabun ve kremlerde geniş kullanımının yanısıra, tekstil, boya, kâğıt sanayinde ve sağlık sektöründe birçok alanda kullanılan bir üründür. Bal mumundan yapılan birçok süs eşyası da bulunmaktadır. Bu çalışmada bal mumu ile ilgili son çalışmalar ışığında ilgili sektörlerinde faydalanabilecekleri yeni bakış açıları sunulması amaçlanmıştır.

Anahtar Kelimeler: Bal mumu, arı sağlığı, kalıntı, gıda kaplama,

\section{ABSTRACT}

Beeswax is the raw material of the honeycomb that the bee colony carries out in its vital activities. Beeswax is also a bee product, such as honey, pollen, royal jelly and bee bread for beekeeping. Because beeswax is an absorbent, it can collect pollutants inside and outside the hive. The bee products produced from this honeycomb pose a risk to human and bee health. Older combs can also provide shelter from pathogenic microorganisms. In particular, honeycomb processing equipments have a very important responsibility for the hygiene of old honeycombs. Beeswax attracts attention with its wide usage area. As a coating agent in the food industry, it is a product used in cosmetics, soap, candle, cream, textile, paint, paper industry, health and many other fields, such as wax sculptures. This study aims to present new perspectives that can be used in relevant fields in the light of recent studies.

Keywords: Beeswax, Bee health, Residues, Food coatings. 


\section{DERLEME MAKALESI / REVIEW ARTICLE}

\section{EXTENDED ABSTRACT}

Introduction: Beeswax is the component of the honeycomb, in which the honeybee keeps its vital needs (honey, pollen) in order to maintain the colony, to regulate vital activities and maintain its hatching activity. The strength of the colony is demonstrated by the number of honeycomb frames in the hive. Beeswax is used as a raw material in many fields. There are many factors, both during production and in the environment, that might threaten the natural state of wax. Honeycombs, the center of many activities in the hive, are exposed to veterinary drug residues and external pollutants applied by beekeepers. In some accommodation areas, the time that bee colonies remain on pollutants and the usage period of old honeycombs can reach levels that threaten sustainable beekeeping and a healthy product production.

Methods and results: In this review, the composition of wax, its usage areas, national and international studies that reveal basic issues are examined. The results are persented in a way to emphasize the importance of beeswax in multiple fields of study.

Beeswax is a component produced by the wax glands in the stomach of young worker bees and created by adding saliva secretions when chewing wax scales. The structure and composition of the wax varies depending on the feeding pattern of the bees, the environment in which they live (flora+pollutants) and the lifespan of the basic combs. Natural wax is a health-promoting product, used in cosmetics, food and many other sectors. It is used as a cream in cosmetics, skin problems, burn treatments and toothpaste in the health sector, in the production of antibacterial fabrics, the textile industry and as a coating base in animal and herbal production. Particularly in the food sector, intensive research has been carried out in order to extend the storage period of fruits and vegetables and increase their shelf life. It has also been used in many products such as eggs, cheddar cheese, salami to improve quality and preserve food.

Beeswax, with its wide usage area, faces multiple negative factors in the production stages and factories where old honeycombs are processed. In particular, the remains of veterinary medicines used for bee diseases/pests and external pollutants are trapped in the wax and appear as residues in products such as honey, pollen, propolis. If old honeycombs collected from beekeepers do not undergo the correct treatment, the risk of spreading diseases and causing many problems in the honeycombs increases.

Conclusion: The most important problems of sustainable beekeeping are insufficient floral resources and pollutants. The original and outsourced pollution by beekeepers contaminates flower and water sources, eventually becoming an environmental crisis. This situation disrupts the continuity of beekeeping and causes the production of residual products. The risk of drug residues should be minimized through accurate diagnosis and timely application of products against pests and diseases. The use of authorized medicines according to the usage instructions and unnecessary use of medicines should be avoided. Instead of saving our day, we should use solutions that save our future. Preventive medicine, which is an important health problem, should also be applied in beekeeping. Therefore, beeswax is a product with a wide usage area and can provide a continuous profit in a residue-free production.

\section{GíRiş}

Bal mumu, bal arısı kolonisi için gıda depolama, kuluçka yetiştirme, termoregülasyon alanı olması yanısıra, arıların iletişimine arabuluculuk eden ve birçok kirletici (patojen, toksin ve atık) için absorban olan çok bileşenli bir malzemedir (Svečnjak v.d. 2019, Buchwald v.d. 2006). Bal mumu birçok farklı özelliği nedeniyle değişik sektörlerde farklı amaçlarla kullanılmaktadır. Tekstil, boya, sağlık, kozmetik, gıda endüstrisi gibi sektörlerin yanında, ağaç kalıp işlemlerinde, ahşap koruyucu olarak, kağıt sanayinde, mum ve balmumundan heykellerin yapımında kullanılmaktadır (Szulc v.d. 2020, Márquez v.d. 2019, Kurtuldu ve Yıldırım 2019, Zhang v.d. 2019, Şen 2019; Eshete ve Eshetie 2018, Souza v.d. 2017, Teker 2015, Khanzadi v.d. 2015, Zhang v.d. 2014, El Sakka v.d. 2013, Tezel 2009, Attam ve Adikwu 2007, Petric v.d. 2004).

Bal mumu ile ilgili tarihi dönemlere ait birçok ize rastlanılmıştır. Antik Mısır kültürü içindeki en büyük kullanım alanlarından biri de mumyalamadır. Ölülerin içine konduğu lahid kapaklarının hava almasını önlemek için bal mumunun yoğun olarak kullanıldığı bilinmektedir (Benson v.d. 1978). Çin'de yapılan kazılarda M.Ö. 6 yüzyılda turkuaz kakmalı bronz kılınç sapında bağlayıcı ajan olarak saf bal mumu kullanıldığı tespit edilmiştir (Luo v.d. 2012). 


\section{DERLEME MAKALESI / REVIEW ARTICLE}

Yine Almanya'da buzul döneminde yapıştırıcı ajan olarak bal mumu kullanıldığı tespit edilmiştir (Baales v.d. 2017).

Bal mumu, bal ve diğer arı ürünleri gibi ekonomik değeri olan bir üründür. Bir kilogram bal mumundan üretilen petek bir kilogram baldan daha değerlidir (Eshete ve Eshetie 2018). Bal gibi bal mumu da büyük ilgi gören birkaç terapötik özellik taşımaktadır. Özellikle diş çürükleri ile iltihap ve yanıkların iyileştirilmesinde etkili olduğu düşünülmektedir. Son yıllarda yapılan araştırmalarda bal mumu ve bal mumu/zeytinyağı ve bal mumu/bal kombinasyonları halinde antimikrobiyal ve antifungal etkileri açığa çıkarılmıştır (Fratini v.d. 2016).

Bal mumunda ana kirlenme kaynağı arıcılıkta kullanılan akarisitlerdir (Bogdanov 2004). Bal mumundan temel petek eldesi sürecinde 2 önemli nokta bulunmaktadır. Birincisi bal mumunun, arı hastalıklarının bulaşması açısından yüksek riskli taşıyıcı olması ve buna bağlı olarak, bal mumundaki patojenlerin saptanması önemlidir (Svečnjak v.d. 2019). Farklı arı işletmelerinden toplanan kullanılmış petekler doğru işlemlerden geçmezse patojenlerin diğer arı işletmelerine yayılmasına neden olabilir. İkincisi ise doğal ürün olarak nitelendirilen bal mumunda çevresel kirleticiler ve arı yetiştiricilerinin bilinçsiz ve gelişi güzel ilaç kullanımı sonucu kalıntı birikmesidir (Valdovinos-Flores v.d. 2017, Karazafiris v.d. 2011).

\section{BAL MUMUNUN BILEŞimi}

Bal mumu, genç işçi arıların karnında (12 ila 18 gün arasında, yani arıların hemşire olarak hareket ettiği sürenin sonunda) özel bal mumu bezleri tarafından sentezlenir. Bal arılarının ön ayakları ile alt çenelerine aktardığı bal mumu pulları çiğnendiğinde tükürük salgıları da inşa edilecek temel peteğe eklenir (Hepburn v.d. 2014, Chauvin 1968). Arılar tarafından salgılandığında, saf bal mumu büyük oranda beyazdır. Sadece bal ve polen ile temas ettikten sonra yoğun sarımsı renk alır ve birkaç yıl sonra kahverengiye dönüşmektedir (Hepburn v.d. 1991). Renk değişikliğinde kuluçka faaliyeti etkili olmaktadır. Çok kullanılan petekler kısa sürede kahverengi renk almaktadır. Absorbe özelliğinden dolayı kalıntı riskinin artması ve kullanıldıkça yavru gözlerinde görülen küçülmeler nedeniyle peteklerin 2 yıl kullanılması önerilmektedir.

Dört bal arısı türüne ait (Apis mellifera L., Apis andreniformis L., Apis dorsata L. ve Apis cerana
L'nin iki alt türü) bal mumlarının mekanik özellikleri karakterize edilmiştir. Apis dorsata bal mumu daha sert ve oransal sınırda diğer bal mumlarının hepsinden daha yüksek akma gerilimi ve stresine sahipken $A$. cerana ve $A$. mellifera mumları ara mukavemet ve sertliğe sahip bulunmuştur. $A$. Andreniformis bal mumu ise en az güçlü, sert ve dirence sahip bal mumudur. Mumların tümü, oransal sınır ve akma noktasında benzer gerilim değerleri göstermiştir. Bal mumunun mekanik özelliklerinde gözlenen farklılıkların, bu türlerin yuvalama ekolojisi ile ilişkili olduğu bildirilmiştir. $A$. mellifera ve $A$. cerana, yuvayı çevresel streslerden koruyan boşluklarda yuva yaparken, en güçlü ve sert bal mumu olan türler $A$. dorsata, uzun ağaçların dallarına bağlı nispeten ağır yuvalar inşa ederek, onları büyük ölçüde daha büyük mekanik kuvvetlere maruz bırakmaktadır. (Buchwald v.d. 2006).

Asya ve Avrupa bal arılarından elde edilen bal mumlarının fiziksel özelliklerinin karşılaştırıldığı bir çalışmada, karbon zinciri uzunluğunun ortalama olarak Asya bal mumlarında A. mellifera'dan daha kısa olduğu ve daha düşük erime noktalarına sahip oldukları görülürken, Avrupa mumları A. mellifera' ya daha benzer bulunmuştur. Bal mumundaki ana bileşik grupları alkanlar, alkenler, serbest yağ asitleri, monoesterler, diesterler ve hidroksimonesterler iken, yağ alkolleri ve hidroksodiesterler minör bileşenlerdir. Bal arısı türleri arasında bal mumu türlerinde belirgin türlere özgü farklılıklar bulunsa da hepsi homolog nötr lipitlerin kompleks bir karışımıdır (Hepburn v.d. 2014).

Bal mumu, hidrokarbonlar (\%14), monoesterler (\%35), diesterler (14-0), triesterler (\%3), hidroksi monoesterler (\%4), hidroksipoliesterler (\%8), serbest asitler $(\% 12)$, asit monoesterler (\%1), asit polyesterler (\%2) ve tanımlanmamış maddelerden (\%7) oluşmaktadır (Tulloch 1971). Bal mumunda bulunan flavonoidler ilk defa Tomás-Barberán v.d. (1993) tarafından pinokembrin, pinobanksin, pinobanksin 3-asetat, chrysin, galangin ve techtochrysin ana flavonoid bileşenleri olarak tespit edilmiştir. Aynı flavonoid bileşiklerinin genellikle aynı coğrafi bölgeden toplanan bal, propolis ve bitkilerde de bulunduğu bildirilmiştir.

İşçi bal arıları, öğrenilen bir petek ile genetik benzerlik temelinde petekler arasında ayrım yapabilir. Petekten (bal mumundan) aldıkları yuva arkadaşı tanıma ipuçlarının da genetik olarak ilişkili bir bileşeni vardır. İşaretler petekte çok kısa maruz 


\section{DERLEME MAKALESI / REVIEW ARTICLE}

kalma sürelerinde ( 5 dakika veya daha az) alınır ve fiziksel temasta olan arılar arasında aktarılabilmektedir. Bu sonuçlar bal arısı kovan arkadaşı tanımada petekten türetilmiş tanıma ipuçlarının oldukça önemli olduğu hipotezini desteklemektedir. Bu ipuçları, bal mumu tarafından emilen çiçek kokularından ziyade, en azından kısmen bal mumunun kendisinden kaynaklanmaktadır (Breed v.d. 1995). Bal mumundaki yağ asitleri de sosyal sinyaller olarak hizmet ettiğinden, yağ asitlerinin fonksiyonel önemi bulunmaktadır. Yağ asitlerinin bal mumundan çıkarılması, bal mumu örneklerinin verim stresi, esnekliği, sertliği ve oransal limit stresinde azalma ile sonuçlanmaktadır. Bal mumuna stearik asit eklenmesi, esneklik hariç tüm bu özellikleri arttırmaktadır. Yapay bal mumu karışımları, bal mumu karışımındaki stearik asit miktarı ile akma gerilimi arasında pozitif bir korelasyon göstermektedir. Bal mumunda bulunan doymamış yağ asitleri, yapay balmumu karışımlarının mekanik özellikleri üzerindeki etkileri açısından benzerdir. Yağ asidi konsantrasyonu koloniler arasında önemli farklılıklar göstermektedir (Buchwald v.d. 2009).

Farklı enerji besleme türlerinin T1 (şeker kamışı suyu), T2 (şeker şurubu) ve T3 (ters şeker-invert şeker) bal mumu üretimi ve ekonomik fizibilitesine etkisinin değerlendirildiği çalışmada; ortalama ters şeker tüketimi, diğer gruplardan önemli ölçüde daha düşük bulunmuştur. En yüksek bal mumu üretim ortalaması şeker şurubu grubunda elde edilmiştir. Şeker kamışı suyunda, ters şeker ve şeker şurubunda sırasıyla en yüksek kül, kuru madde ve indirgeyici şeker ortaya çıkmıştır. Şeker kamışı suyu daha kârlı olmasına rağmen, bal mumu üretimi için alternatif bir enerji kaynağı olabileceği bildirilmiştir (Carrillo v.d. 2015).

\section{BAL MUMUNUN KULLANIM ALANLARI}

\section{Gıda Sektöründe Kullanım}

Biyopolimerik kaplamalar, meyve ve sebzelerin kimyasal ve duyusal özelliklerinin uzun süreli depolanmalarda korunma açısından etkilidir. Bal mumunun (BW), çalışmada kullanılan diğer biyopolimerlere kıyasla hidrofobik bir ajan olarak $\% 10$ oranında ilave edildiğinde su buharı iletim hızında en iyi sonuçları verdiği tespit edilmiştir. Yine kontrollü ortamda 15 gün boyunca meyvelerin yeterli olgunlaşmasını gösteren kilo kaybını en aza indirdiği görülmüştür (Oliveira v.d. 2018). Tayvan'da \%2 bal mumu ile kaplanmış yeşil hünnap meyvesinin su kaybını önemli ölçüde azaltabildiğini ve solunum yoğunluğunu önleyebildiğini, ayrıca brix ve titre edilebilir asit içeriğini etkili bir şekilde koruduğu ifade edilmiştir (Zhao v.d. 2011). Nektarin meyvelerinin raf ömrünün arttırılmasında $\% 4.5 \mathrm{CaCl}_{2}$ ile $\% 3$ bal mumu karışımının kullanılabileceği bildirilmiştir (Seleshi v.d. 2019). Papaya solunum hızının, karides kabuğu atıklarından elde edilen kitosan veya bal mumundan türetilmiş bir polisakkaritin meyvelerin yüzeyinde kaplanması sayesinde inhibe edildiği rapor edilmiştir. Yapılan çalışma sonuçları, kitosan ve bal mumu ile meyve kaplamasının Papaya callina'nın raf ömrünü, depolama sırasında papaya meyvelerinin solunum hızını inhibisyonuna kıyasla dört ila beş gün uzatabildiği belirlenmiştir (Mukdisari v.d. 2016).

Bir başka çalışmada ise hindistan cevizi yağı ve bal mumu kaplaması ile modifiye atmosferik ambalajın (MAP), ortam depolamasında limonun hasat sonrası depolama kalitesi üzerindeki etkisi incelenmiştir. Çalışma sonuçları yalnızca hindistan cevizi yağının ve özellikle MAP ile bal mumu hindistan cevizi karışımlı (10:90 veya 20:80) kaplamaların limonlarda, yeşil renk tutulması, solunum azaltılması, etilen üretimi, kilo kaybı ve büzülme, depolama boyunca limonun sıkılığını ve nem içeriğinin korunmasında faydalı etkiler gösterdiğini ortaya çıkarmıştır (Nasrin v.d. 2020).

Gliserol içeren filmler hazırlamak için jelatin içine farklı oranlarda balmumu veya karnauba mumu ilave edilmiştir. Bal mumu ilavesi ile jelatin filmlerin opaklığı ve sarılığı artmış, hem UV / görünür ışık hem de su buharı bariyerleri, artan bal mumu seviyeleri ile kademeli olarak başarılı bir şekilde iyileşmiştir. Bal mumu seviyesi arttıkça, filmler daha kırılgan, sert ve daha az gerilebilir hale gelmiştir. Tüm filmlerin DPPH ve demir indirgeme testleri antioksidan aktivite içerdiklerini göstermiştir. Jelatin bal mumu filmlerinin gelişmiş bariyer özellikleri ve termal stabilite açısından gıdaların bozulmasına karşı kullanılabileceğini ve jelatin filmlere ilave edildiğinde bal mumunun karnauba mumundan daha etkili olduğu bulunmuştur (Zhang v.d. 2018).

Fıstıkta bal mumu kullanımının halen kullanımda olan hidrojene veya tropikal yağlar gibi mevcut stabilizatörlerin değiştirilmesine yol açabileceği, böylece doymuş yağların azaltılması sonucu ürünlerin daha sağılıklı olacağı bildirilmiştir (WinklerMoser v.d. 2019). 


\section{DERLEME MAKALESI / REVIEW ARTICLE}

Tavuk yumurtalarının sağlıklı ve uzun raf ömrü için bal mumunun jelatine göre daha iyi bir kaplama malzemesi olduğu ve bu yumurtaların 6 hafta boyunca $30^{\circ} \mathrm{C}$ 'de başarılı bir şekilde saklanabileceği rapor edilmiştir (Mudannayaka v.d. 2016).

Yapılan bir çalışmada kaşar peyniri olgunlaştırılması sırasında (120 gün) bal mumu ile kaplamanın mikrobiyolojik, fizikokimyasal ve duyusal özelliklere etkileri araştırıımıştır. Kaşar peyniri örnekleri iki farklı kalınlıkta bal mumu (tek katmanlı kaplama -BW1 ve çift katmanlı kaplama- BW2) ile kaplanmıştır. Karşılaştırma amacıyla vakumla ambalajlanmış (VP) ve ambalaj malzemesi olmadan (kontrol) kaşar peyniri örnekleri kullanıımıştır. Çalışma sonuçları bal mumu ile kaplanmış ve vakumla ambalajlanmış kaşar peynirleri arasında, toplam aerobik mezofilik bakteriler, laktobasiller, koli form bakteriler ve $S$. aureus sayılarında herhangi bir farklılık olmadığını göstermiştir. Mikrobiyolojik analizler ayrıca bal mumu kaplı peynirlerin 120. günde kontrole kıyasla mikrobiyal yükte 2.5 logaritmik birim azalma sağladığını ortaya çıkarmıştır. Kontrol kaşar peynirinde önemli ölçüde $(P<0.05)$ yüksek kuru madde, yağ ve protein içeriği tespit edilirken bal mumu (BW1) uygulaması nem kaybını geciktirerek kalın bir kabuk tabakasının oluşumunu azaltmıştır. Diğer uygulama örneklerine kıyasla, kontrol ve BW1 kaşar peynirlerinin depolama sonunda daha yüksek suda çözünür azot (WSN) ve olgunlaşma indeksine sahip olduğu belirlenmiştir. Duyusal analiz sonucunda, BW1 kaşar peyniri ve kontrol uygulaması panelistler tarafından daha çok tercih edilirken, vakum uygulaması yapılan örnek en düşük puanı almıştır (Yilmaz ve Dagdemir 2012).

Farklı bir çalışmada ise bal mumunun farklı gliserol molekülleri içeren soya protein filmlerinin fonksiyonel ve yapısal özelliklerine etkisi incelenmiştir. Kaplama yapısında balmumu arttığında elastikiyetin, su buharı geçirgenliğinin ve saydamlığın azaldığını, ancak gerilme mukavemeti ve oksijen geçirgenliğinin arttığı tespit edilmiştir. Gliserol miktarının artması filmde su buharı geçirgenliğini, oksijen geçirgenliğini ve şeffaflığı arttırmaktadır. Diferansiyel tarama kolorimetrisi ve Fourier dönüşümü kızıötesi spektroskopi sonuçları bal mumunun film matrisini oluşturmak için gliserol ile bağlanıp soya proteini ile çapraz bağlar yaptığını göstermiştir (Li v.d. 2011).

Gıdaların bal mumu ile kaplanması, yağ ve pigmentlerin oksidasyonunu ve su kaybını önlemeye yardımcı olacak oksijen, ışık ve buhara karşı bir engel oluşturmaktadır. İtalyan salamında bal mumu ile kaplamanın 2-tiyobarbitürik asit reaktif madde (TBARS) ve su aktivitesi (Aw) miktarları üzerinde 55 günlük olgunlaşma süresince etkilerini değerlendirmek için bir çalışma yapılmıştır. Ayrıca 5, 6 ve 7 aylık raf ömründeki kontrollerle karşılaştırılmıştır. Sonuçlar duyusal kalite çalışmaları ile doğrulanmıştır. Bal mumu kaplı salamda 6 aylık olgunlaşmaya kadar (medyan 0.697, max 0.795) TBARS seviyeleri $0.8 \mathrm{mg} \mathrm{kg}^{-1 \text { in }}$ altında iken kaplanmamış salamda (medyan 1.176, max 1.227) gibi önemli ölçüde daha yüksek değerler tespit edilmiştir. Çalışma sonucunda bal mumu kaplamasının İtalyan salamının sertleşmesini önlediği ve soyulmayı kolaylaştırdığı bildirilmiştir (Trevisani v.d. 2017).

Elmanın soğuk hava depolarında saklanması için yenilebilir bir kaplama karışımı (\% 5 propolis ve $\% 95$ bal mumu) hazırlanmış ve bu kaplamaya Drosophila melanogaster Meigen (1830) larvaları aşılanarak yaşama gelişimi takip edilmiştir. Yeni kaplama karışımının larvaların gelişim sürelerini yaklaşık bir gün geciktirmiştir. Diğer kaplama materyali ile beslenen ergin bireyler deney grubunda bulunanlara oranla daha sert tespit edilmiştir. Bu sonuçlara göre kaplama olarak bal mumunun kullanılmasının, beslenme sonrası ürünün doğaya atıldığında diğer canlılara da zarar vermeyeceğinden uygun olacağı bildirilmiştir (Güneş v.d. 2019).

\section{Hayvancılıkta Kullanım}

Hayvancılıkta besin maddelerin yararlıı̆̆ını artırmak amacıyla çeşitli uygulamalar yapılmaktadır. Özellikle besin maddesinin istenilen yerde sindirimin yapılması ve emilimin sağlanması amaçlanmaktadır. Yetişkin koyunların beslenmesinde bal mumuna mikro kapsüllenmiş yavaş salınan üre dahil edilmesinin alım, sindirilebilirlik ve azot (N) dengesi üzerindeki etkilerini değerlendirmek için bir çalışma yürütülmüştür. Çekirdek (üre) ve enkapsülan (bal mumu) arasında 1:2 ( $\bigcup_{M E}$ 1:2) ve 1:2+kükürt ( $\bigcup_{M E}$ $1: 2+S)$ oranları ile iki mikro kapsüllenmiş sistem formülasyonu geliştirilmiştir. $\bigcup_{\mathrm{ME}} \quad 1: 2$ formülasyonunun, $U_{M E} 1: 2+S$ 'den daha yüksek verim değerlerine, mikro kapsülleme verimliliğine ve termal kararlılığa sahip olduğu bildirilmiştir. En verimli formülasyon ( $\left.\bigcup_{M E} 1: 2\right)$ ortalama vücut ağırlığı $28.2 \mathrm{~kg} \pm 0.6 \mathrm{~kg}$ olan yirmi dört adet yetişkin erkek koyun diyetine eklenmiştir. Bal mumuna mikro kapsüllenmiş üre dahil edilmesi kurumadde, ham protein, eter özütü, kül, toplam karbonhidrat, ham 


\section{DERLEME MAKALESI / REVIEW ARTICLE}

enerji alımı veya sindirilebilirliği etkilenmediği bildirilmiştir $(P>0.05)$. Kapsüllenmiş üre içerme seviyesi \%0'dan 4.5 'e yükseldiğinden nötr deterjan lifi (NDF) $(P=0.031)$ ve asit deterjan lifi (ADF) $(P=$ 0.004) sindirilebilirlikte doğrusal bir artış olmuştur. Lifsiz karbonhidrat (NFC) sindirilebilirliği ikinci dereceden bir artış göstermiştir $(P<0.001)$. \%3.0 mikro kapsüllü üre ile en büyük sindirilebilirliğe sahip olduğu bildirilmiştir. Bal mumunun üre içeren mikro partiküller elde etmek için etkili bir mikro kapsülleyici olduğu gösterilmiş ve $S$ ilave edilmeden $\bigcup_{M E}$ 1:2 formülasyonu, $S$ ile yapılan formülasyondan daha iyi verim gösterdiğinden \%4.5'e kadar dahil edilmesi önerilmiştir. Bal mumu lipit matrisinde mikro kapsüllenmiş üre, alım ve $\mathrm{N}$ dengesini etkilemeden NDF ve ADF sindirilebilirliğini artırmak için tavsiye edilmiştir (Carvalho v.d. 2019).

Başka bir çalışmada taze polen topaklarının (köfte) ve polen toplarının bal mumu ile kaplanmasının bombus arılarının yaşam parametreleri ve polen tüketimleri üzerine olası etkileri ele alınmıştır. Koloni başlangıç aşamasında balmumu ile kaplı polenleri kullanmamış ancak sonraki iki aşamada yani koloni temel aşaması ve koloni olgunlaşma evresinde, bir kat bal mumu içeren polen köftesini tercih etmiştir. Çalışma sonucunda iki aşamada, yaban arısı yetiştiriciliği için en iyi kaplama materyalinin bal mumu olduğu rapor edilmiştir (Imran v.d. 2015).

Yanıklar, dünyada küresel bir halk sağlığı sorunu olup ve tedavi maliyeti yanık sargılarının pahalı olması nedeniyle yüksektir. Özellikle ikinci derece yanıkların tedavisi çok acı verici olmakla birlikte bu yanıklar için ideal pansuman materyali tespit edilememiştir. Bu konuda yapılan bir çalışmada, gümüş sülfadiazin (SSD) ve bal ile balmumu ve zeytinyağı (MHBO) karışımlarının ikinci derece yanıklarda etkisi deney hayvanları üzerinde denenmiştir. Deney hayvanları üzerinde $\mathrm{MHBO}$, SSD \%1 krem ve kontrol grubu (topikal tedavi yoktur) oluşturulmuştur. Tedavinin etkinliği yaranın iyileşme yüzdesi, yara iyileşmesini tamamlama süresine ve iltihaplanma ve eksüdasyon derecesine göre değerlendirilmiştir. Yaranın tam olarak kapanması için ortalama süreler MHBO ve SSD için sırasıyla $21.9 \pm 2.23$ ve $24.7 \pm 2.39$ gün olarak bulunmuştur. Klinik olarak, inflamatuar reaksiyon ve eksüdasyon MHBO grubunda SSD ve kontrol grubuna göre daha azdır. Topikal MHBO kullanımı, hem kontrol hem de SSD gruplarına kıyasla yanık yara iyileşme sürecini hızlandırmış ve gelecekte yardımcı veya alternatif bir ajan olarak kullanılabileceği bildirilmiştir (Moustafa ve Atiba 2015). Bir başka çalışmada diyabetik tavşanların yaralarında balmumu merhemi kullanımının pozitif bir iyileşmeye (terapötik etki) yardımcı olduğu tespit edilmiştir (Fu v.d. 2005).

\section{Bitkisel Üretimde Kullanım}

Boylu maviyemiş (Vaccinium corymbosum L.)'in çelikle üretilmesinde hormon ve ortamın etkisinin tespit edildiği bir çalışmada çelik uçlarının su kaybını önlemek için bal mumu kullanılmıştır (Turna v.d. 2013).

\section{Sağlıkta Kullanım}

Bal mumunun sağlık amaçlı kullanımı çeşitlilik göstermektedir. Slovenya'da tespit edilen insan çene fosillerinde 6500 yıl önce diş dolgusu olarak olarak kullanıldığı bildirilmiştir (Bernardini v.d. 2012).

Bal mumu-zeytinyağı-tereyağı karışımının deney sıçanlarında oluşturulan ikinci derece yanık dokularında yanık yara iyileşmesini geliştirdiğini ve TGF- $\beta 1$ (Dönüştürücü büyüme faktörü) ve VEGF- $\alpha$ (Vasküler endotelyal büyüme faktörü-alfa) modüle edici doku yoluyla cilt yenilenmesini teşvik ettiğini bildirilmiştir (Bayir v.d. 2019). Yine bal mumu, zeytinyağı ve A.tinctoria (L.) Tausch karışımı ikinci derece yanık vakalarında epitel doku gelişimini hızlandırmış, pansuman değişiklikliği sırasında yaşanan ağrıyı azaltmış ve hastaların daha kısa sürede taburcu olmasını sağlamıştır (Gümüş ve Özlü 2017). Bal mumu ve bitkisel yağ kreminin, yanık sonrası kaşıntı semptomlarında tıbbi kremlerden daha etkili olduğu bildirilmiştir. Bal mumu ve bitkisel yağ kreminin etkinliğini inceleyen daha geniş bir çalışma yapılmasının gerekli olduğu ifade edilmiştir (Lewis v.d. 2012).

Bal, bal mumu ve zeytinyağı karışımının (1:1:1, v/v) bebek bezi dermatiti, sedef hastalığı ve egzama tedavisinde faydalı olduğu (AI-Waili 2005) mantar enfeksiyonlarının tedavisinde bal, zeytinyağı ve bal mumu (1:1:1) kullanıldığında; Pitriyazis versikolor'lu (PV) hastaların \%86'sında, Tinea cruris li hastaların $\% 78$ 'inde ve Tinea corporis'li hastaların \%75'inde klinik yanıt alındığı bildirilmiştir (Al-Waili 2004). Hemoroit ve anal fissür tedavisinde bal, zeytinyağı ve bal mumu karışımının güvenli ve klinik olarak etkili olduğu bildirilmiştir (Al-Waili v.d. 2006). Yine bal, propolis, zeytinyağı ve bal mumu karışımının kemoterapideki hastaların oral mukozit tedavisinde kullanılabileceği rapor edilmiştir (Abdulrhman v.d. 2012).

Bal mumu geri dönüşüm işleminden elde edilen iki yan ürünün (MUD 1 ve MUD 2 kodlu) fitokimyasal 


\section{DERLEME MAKALESI / REVIEW ARTICLE}

içerikleri, antioksidan etkileri ile kanser hücreleri ve sitotoksik etkilerinin incelendiği çalışmada MUD 1'in en yüksek $(P<.05)$ lif, protein, karbonhidrat, polifenol ve flavonoid konsantrasyonuna sahip olduğu, doza bağlı bir şekilde mitokondriyal işlevselliği etkileyerek HepG2 hücreleri üzerinde antikanser aktivitesi gösterdiği bildirilmiştir (Giampieri v.d. 2018).

Bal mumu ilk kez polyester / pamuk / viskon ve polyester kumaşa uygulanmış ve bu kumaşların antimikrobiyal etkinlik olarak düşük biyostatik aktivite içerdikleri bildirilmiştir. İstisna olarak, Aspergillus niger küfü ve Bacillus subtilis bakterisine karşı polyester kumaş biyostatik etki göstermiştir. Elde edilen sonuçlar bal mumu içeren kumaşların sağlık ve sosyal bakım kurumlarında ve özellikle sporcuların ve hassas cilt enfeksiyonları olan kişiler için üretilecek tekstil ürünlerde kullanılabileceğini ortaya koymuştur (Szulc v.d. 2020).

\section{BAL MUMUNUN TEMEL SORUNLARI}

Arı hastalık ve zararılıarına karşı arıcıların kullandığı veteriner ilaçlar iç kaynaklı ve çiftçiler tarafından kullanılan bitki koruma ilaçları da dış kaynakı olarak balmumuna geçmekte ve kalıntı sorunlarına yol açmaktadır.

\section{Çiftçi Kaynaklı Kirleticiler}

İspanya'da farklı çevre koşullarında yapılan üretimlerde alınan polen ve bal mumu örneklerinde ilaç kalıntı düzeyleri incelenmiş, pestisitlerin yoğun olarak polen örneklerinde olduğu ve bitki çeşitlerine göre tespit edilen ilacın değiştiği belirlenmiştir. Bal mumu örneklerinin \%75'inden fazlasında ise yoğunlukla koumaphos, klorfenvinfos, fluvalinat ve akrinatrin gibi yüksek seviyelerde mitisitleri saptanmıştır. Bal mumunun en kirli ve bal arıları için en yüksek ortalama tehlike skorlarını (HQ> 5000) sahip olduğu belirlenirken polen numuneleri en fazla sayıda pestisit kalıntısı ve arılar için tehlike $(H Q>50)$ içerdiği belirlenmiştir. Bal mumu ve polen örneklerinde tehlike katsayısı puanlarına en önemli katkıyı akinatrin yapmıştır (Calatayud-Vernich v.d. 2018).

2013-2015 yılları arasında İtalyan kovanlarından elde edilen balmumunda kalıntı miktarı belirlenmesi amacıyla toplanan 178 bal mumu örneğinde 247 pestisit aranmıştır. Örneklerin \%73.6'sında bir veya daha fazla pestisit bulunmuş olup numunelerde ortalama olarak Avrupa'da yasaklanmış veya İtalya'da izin verilmeyen on dört bileşik içeren ortalama üç farklı pestisit tespit edilmiştir. Bu tespitler kumaraphos (numunelerin \%60.7'si), taufluvalinat (\% 50$)$ ve klorfenvinfos (\%35.4) ile ilişkilendirilmiştir (Perugini v.d. 2018).

Bal ve bal mumunda eser elementlerin ve pestisitlerin bulunması tüketiciler için sağık açısından tehlike oluşturabilmektedir. İsrail'de bir çalışmada bal ve bal mumu örneklerindeki pestisitlerin ve eser elementlerin insanlar için risk değerlendirmesi amaçlanmıştır. Bulgular en az iki pestisitin, bal ve bal mumu örneklerini aynı anda kontamine ettiğini, amitraz metabolitleri ve coumaphos'ında sıklıkla tespit edildiği bildirilmiştir. Neonikotinoid insektisitler ve 2,4diklorofenoksiasetik asit sadece bal örneklerinde bulunurken, daha fazla lipofilik böcek ilacı ağırlıklı olarak bal mumunda tespit edilmiştir. Balda krom ve çinko metalleri en yüksek konsantrasyonda iken bal mumunda sadece kurşun ve molibden belirlenmiştir. Sonuç olarak günlük bal ve bal mumu tüketiminin birlikte çocuk sağlığını tehlikeye atabileceği bildirilmiştir (Bommuraj v.d. 2019).

Kırklareli İli civarında arıcılık yapan 57 üreticiden petek örneklerinde streptomisin, tetrasiklin, kloramfenikol antibiyotikleri ile imidacloprid, tribenuron metil, propargit ve pendimethalin pestisit kalıntı varlığı izlenmiştir. Analiz sonuçları bölgeden toplanan peteklerde herhangi bir antibiyotik kalıntısının bulunmadığını göstermiştir. Pestisitler açısından bakıldığında ise imidacloprid ve tribenuron metil analizine göre 57 örneğin 4 tanesinde pendimethalin seviyesi maksimum kalıntı seviyesi (MRL) düzeyi olan 50 ppb"nin üzerinde tespit edilmiştir. Propargit Avrupa Komisyonu tarafından yasaklanmış bir akarisittir. Analizi yapılan 57 örneğin 11 tanesinde bu akarisite sınır değerin üzerinde rastlanmıştır (Saygılı 2017).

\section{Arıcı Kaynaklı Kirleticiler}

Temel balmumu tabakalarının işlenmiş temel peteğe göre daha yüksek kirletici konsantrasyonları ve daha fazla bileşik çeşitliliği içerdiği bildirilmektedir. Yapılan bir çalışmada kirleticiler ile eklenmiş saflaştırıımış bal mumunun kaynar suyunda tekrarlanan erime, amitraz ve klordimeform hariç, bal mumundaki kirletici maddelerin çoğunun içeriğini önemli ölçüde değiştirmediği ve bu da kirleticilerin kararlı olduğunu ve saflaştııılmış bal mumunda bulunduğunu göstermektedir (Jiménez v.d. 2005).

İspanya'da bal mumu örneklerinden fizikokimyasal parametrelerin parafin, stearik asit, karnauba mumu 


\section{DERLEME MAKALESI / REVIEW ARTICLE}

ve donyağı ile karışımları tespit etmek için yürütülen çalışmada $\% 5$ veya daha yüksek düzeyde karıştırma olduğu belirlenmiştir. Arılar tarafından reddedilen veya kötü kabul gören temel peteklerde 27 bal mumu örneğinden 25 'i en az bir parametre için anormal değerler göstermiştir (Bernal v.d. 2005). Yine İspanya'da 2016 yılı boyunca toplanan temel petek, eski petek, doğal peteklerde pestisit içerikleri incelenmiştir. Doğal petekler en az kirlenmeye maruz kalmıştır. En yoğun kalıntı eski petek mumunda tespit edilmiştir. Kovan içine uygulanan mitisitlerin ortalama pestisit yüküne $\% 95$ 'in üzerinde bir katkısı olduğu bildirilmiştir. Akarisit olarak yaygın olarak kullanılan koumaphos (\%100), fluvalinat (\%86) ve amitraz (\%83) en sık saptanan böcek ilaçlarıdır. Klorfenvinfos \%77, akrinatrin \%71 ve flumetrin $\% 54$ ve ayrıca akarisitler tespit edilmiştir. Bitkilerde kullanılan pestisitlerin frekansları klorpirifos için \%40, diklofenthion için \%29, malathion için $\% 9$, fenthion-sülfoksit için $\% 6$ ve azinfos-metil, karbendazim, etion, hexythiazox, imazalil ve priproksifen için \%3 düzeylerde olduğu bildirilmiştir (Calatayud-Vernich v.d. 2017).

Bal mumunda coumaphos kalıntısı özellikle kraliçe arıların gelişimini olumsuz etkilemektedir. Bu konuda yapılan bir çalışma bir kraliçe hariç tüm kraliçe arıların $1000 \mathrm{mg} / \mathrm{kg}$ coumaphos'un gelişme ve pupa dönemi ağırlığını olumsuz etkilediği bildirilmiştir. Kraliçe yetiştirme hücrelerinde coumaphos'un varlığı, altı ayda kolonilerde hala işlev gören kraliçe sayısını \%75'e kadar azaltabilmiştir (Collins v.d. 2004). Bal mumunda akarisitlerin varlığının, yavruların hayatta kalmasını olumsuz etkilediği bildirilmiştir. Pestisit konsantrasyonu azaldığında, hayatta kalma oranında bir iyileşme olmaktadır. Parafin mumu içermeyen bal mumu temelinde geliştirilen, daha yüksek kirletici kalıntı konsantrasyonunda maruz kalan larvalar, akarisitlerin toksik etkilerine karşı daha savunmasız olmaktadır (Medici v.d. 2012).

Belçika'da rastgele 124 bal mumu örneğinde flumetrin kalıntısının sağlık riski açısından analiz edilmiştir. Bal mumu sağlığında flumetrin kalıntılarının maruz kaldığı risk bir tehlike oranının hesaplanmasıyla değerlendirilmiştir. Bireysel tüketim verilerinin eksikliği nedeniyle bal mumu tüketimi için olasılıksal yaklaşım mümkün olmadığı ve tahmin edilen en yüksek maruziyet, teorik maksimum günlük alım miktarının $\% 0.1$ 'inden az olduğu bununda insan sağlığı için hiçbir risk oluşturmayacağı ifade edilmiştir (El Agrebi v.d. 2019).
Bal mumu güvesi (Galleria mellonella L.) larva evrelerinde ballı, polenli ve yavrulu petekler üzerinde beslenirken, bal mumunda da zarara neden olur. Yapılan bir çalışmada, eski kabartılmış peteklerden, temel petek üreten 4 işletmeden alınan temel peteklerin, başlangıç düzeyleri kalıntı miktarlarındaki değişim havalandırılma sonucundaki kalıntı miktarları belirlenmiştir. Başlangıçta ortalama kalıntı miktarı, $21.48 \pm 3.657 \mathrm{ppb}$ iken, 60 gün havalandırma sonrasında $7.97 \pm 0.764 \mathrm{ppb}, 120$ gün sonra $6.22 \pm 0.290 \mathrm{ppb}$ ve 180 gün sonra da $5.41 \pm 0.332$ ppb olarak saptanmıştır. Sonuç olarak, temel peteklerin 60 gün havalandırma ile kalıntı miktarının önemli düzeyde $(P<0,05)$ azaldığı belirlenmiştir (Bağçe 2008).

\section{SONUÇ}

Tarım ve hayvancılıkta verimi arttırmak ve üst düzeye çıkarmak için son zamanlarda yoğun kullanılan insektisit, herbisit, fungisit ve bakterisitler kullanıldığı bitkiyi korusa da çevrede yarattığı büyük kirlilik tüketilecek olan gıda ürünlerinde kalıntı olarak geri dönmektedir. Kirleticiler (pestisit, toksinler, ağır metaller, organik kirleticiler) insan sağlığı için büyük bir sorun haline gelmiştir.

Avrupa ülkelerinde, arıcılıkta kullanılabilecek izinli kimyasallar ve aşılmaması gereken limitler (MRL) bulunmaktadır. Ülkemizde de özellikle varroaya karşı bilinçsizce ilaç kullanımı kalıntı riskini arttırmaktadır. Bu riskin kontrol altına alınması yetkisiz ürünlerin kullanımına son verilmesi ve bilinçli kullanılması ile en aza indirilebilir. Arı ürünlerinde bir diğer sorun arıcıların eski petekleri bal mumu güvesi larvalarından korumak için depolarda kullanılan uçucu böcek ilaçları ve diğer kimyasalları kullanmalıdır. Depolama sırasında kullanılan birkaç kimyasal fumigant risk kaynağıdır. Arıcılar bu bileşikleri kullanmayı bıraksalar da, kalıntılar yıllarca hala eski peteklerde bulunmakta ve gelecek yıllarda üretilecek ürünlerde kalıntı riskinin devamına neden olabilmektedir.

Kirleticiler ve arıcıların ruhsatsız ilaçları kuralsız ve keyfi uygulamaları kovanda mevcut arı ürünlerinin absorbe etme özelliği nedeniyle sağlık açısından risk oluşturmaktadır. Bu nedenle arıcıların üretimlerini kimyasal ilaçlama alanlarından uzak bölgelerde yapmaları teknik arıcılık uygulamalarını kullanmaları kalıntı riskini en çok barındıran bal mumu için kritik bir önemdedir. Geniş kullanım alanları olan bal mumu kalıntı riski bulundurmamalı ve kullananlar 


\section{DERLEME MAKALESI / REVIEW ARTICLE}

için risk ve şüphe taşımamalıdır. Kısacası kovanın geleceği ve sağlığımız için temiz bal mumu üretimi ve temiz çevre şarttır.

\section{KAYNAKLAR}

Abdulrhman, M., Samir Elbarbary, N., Ahmed Amin, D., Saeid Ebrahim, R. 2012. Honey and a mixture of honey, beeswax, and olive oilpropolis extract in treatment of chemotherapyinduced oral mucositis: a randomized controlled pilot study. Pediatric hematology and oncology, 29(3): 285-292.

Al-Waili, NS., Saloom, K. S., AI-Waili, TN., AI-Waili, AN. 2006. The safety and efficacy of a mixture of honey, olive oil, and beeswax for the management of hemorrhoids and anal fissure: a pilot study. The Scientific World Journal, (6): 1998-2005.

Al-Waili, NS. 2005. Mixture of honey, beeswax and olive oil inhibits growth of Staphylococcus aureus and Candida albicans. Archives of medical research, 36(1): 10-13.

Al-Waili, NS. 2004. An alternative treatment for pityriasis versicolor, tinea cruris, tinea corporis and tinea faciei with topical application of honey, olive oil and beeswax mixture: an open pilot study. Complementary therapies in medicine, 12(1): 45-47.

Attama, AA., Adikwu, MU. 2007. Use of trona as a permeation enhancer for ointments prepared with beeswax extracted from native honeycombs. Journal of Pharmaceutical and Allied Sciences, 4(2).

Baales, M., Birker, S., Mucha, F. 2017. Hafting with beeswax in the Final Palaeolithic: a barbed point from Bergkamen. antiquity, 91(359): 1155-1170.

Bağçe, A. 2008. Arıcılıkta kullanılan temel peteklerde naftalin kalıntısının belirlemesi üzerinde bir araştırma (Master's thesis, Adnan Menderes Üniversitesi, Fen Bilimleri Enstitüsü). 54 sayfa. Aydın.

Bayir, Y., Un, H., Ugan, RA., Akpinar, E., Cadirci, E., Calik, I., Halici, Z. 2019. The effects of Beeswax, Olive oil and Butter impregnated bandage on burn wound healing. Burns, 45(6): 1410-1417.
Benson, GG., Hemıngway, SR., Leach, FN. 1978. Composition of the wrappings of an ancient Egyptian mummy. J.Pharmacy and Pharmacol. 30:78.

Bernal, JL., Jiménez, JJ., del Nozal, MJ., Toribio, L., Martín, MT. 2005. Physico-chemical parameters for the characterization of pure beeswax and detection of adulterations. European journal of lipid science and technology, 107(3): 158-166.

Bernardini, F., Tuniz, C., Coppa, A., Mancini, L., Dreossi, D., Eichert, D., Hua, Q. 2012. Beeswax as dental filling on a Neolithic human tooth. Plos one, 7(9), e44904.

Breed, MD., Garry, MF., Pearce, AN., Hibbard, BE., Bjostad, LB., Page Jr, RE. 1995. The role of wax comb in honey bee nestmate recognition. Animal Behaviour, 50 (2): 489-496.

Bommuraj, V., Chen, Y., Klein, H., Sperling, R., Barel, S., Shimshoni, JA. 2019. Pesticide and trace element residues in honey and beeswax combs from Israel in association with human risk assessment and honey adulteration. Food chemistry, 299, 125123.

Bogdanov, S. 2004. Quality and standards of pollen and beeswax. Apiacta, 38:334-341.

Buchwald, R., Breed, MD., Greenberg, AR., Otis, G. 2006. Interspecific variation in beeswax as a biological construction material. Journal of experimental biology, 209 (20): 3984-3989.

Buchwald, R., Breed, MD., Bjostad, L., Hibbard, BE., Greenberg, AR. 2009. The role of fatty acids in the mechanical properties of beeswax. Apidologie, 40(5): 585-594.

Calatayud-Vernich, P., Calatayud, F., Simó, E., Picó, Y. 2017. Occurrence of pesticide residues in Spanish beeswax. Science of The Total Environment, 605: 745-754.

Calatayud-Vernich, P., Calatayud, F., Simó, E., Picó, Y. 2018. Pesticide residues in honey bees, pollen and beeswax: Assessing beehive exposure. Environmental Pollution, 241: 106114.

Carrillo, MP., Kadri, SM., Veiga, N., Orsi, RDO. 2015. Energetic feedings influence beeswax production by Apis mellifera L. honeybees. Acta Scientiarum. Animal Sciences, 37(1): 7376. 


\section{DERLEME MAKALESi / REVIEW ARTICLE}

Carvalho, ADB., da Silva, AL., Silva, ADA., Netto, AJ., de Medeiros, TTB., Araújo Filho, JM., Oliveira, JR. 2019. Effect of slow-release urea microencapsulated in beeswax and its inclusion in ruminant diets. Small Ruminant Research, 179: 56-63.

Chauvin R. 1968. Traite' de biologie de l'abeille. Paris: Masson et Cie.

Collins, AM., Pettis, JS., Wilbanks, R., Feldlaufer, MF. 2004. Performance of honey bee (Apis mellifera) queens reared in beeswax cells impregnated with coumaphos. Journal of Apicultural Research, 43(3): 128-134.

El Agrebi, N., Wilmart, O., Urbain, B., Danneels, EL., de Graaf, DC., Saegerman, C. 2019. Belgian case study on flumethrin residues in beeswax: Possible impact on honeybee and prediction of the maximum daily intake for consumers. Science of the total environment, 687: 712719.

El Sakka, A., Abdulrhman, M., Shehata, IH. 2013. Comparison between topical application of honey, bees wax and olive oil propolis extract and nystatin for treatment of diaper dermatitis in infants. International Journal of Pediatrics and Child Health, 1(4): 39-42.

Eshete, Y., Eshetie, T. 2018. A Review on Crude Beeswax Mismanagement and Lose: Opportunities for Collection, Processing and Marketing in Ethiopia. Research Journal of Food and Nutrition, 2(4): 4-12.

Fratini, F., Cilia, G., Turchi, B., Felicioli, A. 2016. Beeswax: A minireview of its antimicrobial activity and its application in medicine. Asian Pacific Journal of Tropical Medicine, 9(9): 839-843.

Fu, H., Wang, XJ., Lu, HF., Xu, QW. 2007. Experimental study on beeswax ointment in diabetic rabbit's model of wound healing [J]. Journal of Dalian Medical University, 4.

Giampieri, F., Quiles, JL., Orantes-Bermejo, FJ., Gasparrini, M., Forbes-Hernandez, TY., Sánchez-González, C., Cianciosi, D. 2018. Are by-products from beeswax recycling process a new promising source of bioactive compounds with biomedical properties? Food and Chemical Toxicology, 112: 126-133.
Güneş, E., Sert, D., Kübra Erçetin, H. 2019. Bal mumu ve propolis gibi kaplama ürünlerinin böcekteki etkisinin belirlenmesi. Iğdır Üniversitesi Fen Bilimleri Enstitüsü Dergisi, 9(4): 2133-2139.

Gümüş, K., Özlü, ZK. 2017. The effect of a beeswax, olive oil and Alkanna tinctoria (L.) Tausch mixture on burn injuries: an experimental study with a control group. Complementary Therapies in Medicine, 34: 66-73.

Hepburn, HR., Bernard, RTF., Davidson, BC., Muller, WJ., Lloyd, P., Kurstjens, SP., Vincent, SL.1991. Synthesis and secretion of beeswax in honeybees. Apidologie, 22(1): 21-36.

Hepburn, HR., Pirk, CWW., Duangphakdee, O. 2014. The chemistry of beeswax. In Honeybee Nests (pp. 319-339). Springer, Berlin, Heidelberg.

Imran, M., Ahmad, M., Naeem, M., Saeed, S., Nasir, MF., Ahmad, A., Aslam, UA. 2015. Effect of fresh pollen pellets and pollen balls coated with and without beeswax on the life history parameter of bumblebee. Journal of Biodiversity and Environmental Sciences (JBES) Vol. 6, No. 5, p. 144-153,

Jiménez, JJ., Bernal, JL., del Nozal, MJ., Martín, MT. 2005. Residues of organic contaminants in beeswax. European journal of lipid science and technology, 107(12): 896-902.

Karazafiris, E., Tananaki, C., Thrasyvoulou, A., Menkissoglu-Spiroudi, U. 2011. Pesticide residues in bee products. Pesticides in the Modern World-Risks and Benefits, 89-126.

Khanzadi, M., Jafari, SM., Mirzaei, H., Chegini, FK., Maghsoudlou, Y., Dehnad, D. 2015. Physical and mechanical properties in biodegradable films of whey protein concentrate-pullulan by application of beeswax. Carbohydrate Polymers, 118: 24-29.

Kurtuldu, E., Yıldırım, L. 2019. Farklı Kültürlerdeki Rezerve Boya/Baskı Teknikleri Üzerine Kavram ve Terimler. Yedi, (21): 93-103.

Lewis, PA., Wright, K., Webster, A., Steer, M., Rudd, M., Doubrovsky, A., Gardner, G. 2012. A randomized controlled pilot study comparing aqueous cream with a beeswax and herbal oil cream in the provision of relief from postburn 


\section{DERLEME MAKALESI / REVIEW ARTICLE}

pruritis. Journal of Burn Care \& Research, 33(4): e195-e200.

Li, XH., Guo, K., Zhao, XY. 2011. Effect of beeswax on functional and structural properties of soy protein isolate films. In Advanced Materials Research (Vol. 150, pp. 1396-1399). Trans Tech Publications Ltd.

Luo, W., Li, T., Wang, C., Huang, F. 2012. Discovery of Beeswax as binding agent on a 6th-century BC Chinese Turquoise-inlaid Bronze sword. Journal of Archaeological Science, 39(5): 1227-1237.

Márquez, R., Bálsamo, S., Morales, F., Ruiz, N., García, A., León, R., ... Zambrano, J. 2019. Technological use of beeswax for obtaining organic products, non-toxic for the human being Aprovechamiento tecnológico de la cera de abeja para la obten-ción de productos orgánicos, no tóxicos para el ser humano. Revista Ciencia e Ingeniería. Vol, 40(1).

Medici, SK., Castro, A., Sarlo, EG., Marioli, JM., Eguaras, MJ. 2012. The concentration effect of selected acaricides present in beeswax foundation on the survival of Apis mellifera colonies. Journal of Apicultural Research, 51(2):164-168.

Mukdisari, Y., Suketi, K., Widodo, WD. 2016. Fruit Coating with Chitosan and Beeswax to Extend Papaya Shelf Life. Journal of Tropical Crop Science Vol, 3(3).

Mudannayaka, Al., Rajapaksha, DSW., Kodithuwakku, KAHT. 2016. Effect of Beeswax, Gelatin and Aloe vera Gel Coatings on Physical Properties and Shelf Life of Chicken Eggs Stored at $30 \mathrm{C}$. J. World Poult. Res. 6(1): 06-13.

Moustafa, A., Atiba, A. 2015. The effectiveness of a mixture of honey, beeswax and olive oil in treatment of canine deep second-degree burn. Global Veterinaria, 14(2): 244-250.

Nasrin, TAA., Rahman, MA., Arfin, MS., Islam, MN., Ullah, MA. 2020. Effect of novel coconut oil and beeswax edible coating on postharvest quality of lemon at ambient storage. Journal of Agriculture and Food Research, 2, 100019.

Petric, M., Kricej, B., Humar, M., Pavlic, M., Tomazic, M. 2004. Patination of cherry wood and spruce wood with ethanolamine and surface finishes. Surface Coatings International Part B: Coatings Transactions, 87(3):195.

Perugini, M., Tulini, SM., Zezza, D., Fenucci, S., Conte, A., Amorena, M. 2018. Occurrence of agrochemical residues in beeswax samples collected in Italy during 2013-2015. Science of the total environment, 625: 470-476.

Saygılı, M. 2017. Kırklareli ilinde arıcılık faaliyeti yapan üreticilerden toplanan peteklerde antibiyotik ve pestisit kalıntısı aranması (Master's thesis, Namık Kemal Üniversitesi).

Seleshi, G., Woldetsadik, K., Azene, M. 2019. Effect of Calcium Chloride Dipping and Beeswax Coating on the Shelf Life and Quality of Nectarine (Prunus persica (L.) Batsch var. nucipersica) Fruits. Agriculture and Food Sciences Research, 6(1): 71-78.

Souza, C., de Freitas, LAP., Campos, PMBGM. 2017. Topical formulation containing beeswax-based nanoparticles improved in vivo skin barrier function. Aaps Pharmscitech, 18(7): 2505-2516.

Svečnjak, L., Chesson, LA., Gallina, A., Maia, M., Martinello, M., Mutinelli, F., Wallner, K. 2019. Standard methods for Apis mellifera beeswax research. Journal of Apicultural Research, 58(2): 1-108.

Szulc, J., Machnowski, W., Kowalska, S., Jachowicz, A., Ruman, T., Steglińska, A., Gutarowska, B. 2020. Beeswax-Modified Textiles: Method of Preparation and Assessment of Antimicrobial Properties. Polymers, 12(2): 344.

Şen, B. 2019. Yılmaz Büyükerşen Balmumu Heykeller Müzesi Ziyaretçilerinin Taşıma Kapasitesi Ve Memnuniyet Algılarının Değerlendirilmesi. Eskişehir Osmangazi Üniversitesi. Sosyal Bilimler Enstitüsü. Turizm İşletmeciliği Anabilim Dalı. Yüksek Lisans. 103 sayfa.

Oliveira, VRL., Santos, FKG., Leite, RHL., Aroucha, EMM., Silva, KNO. 2018. Use of biopolymeric coating hydrophobized with beeswax in postharvest conservation of guavas. Food chemistry, 259: 55-64. 


\section{DERLEME MAKALESI / REVIEW ARTICLE}

Teker, MS. 2015. Kapatma Maddesi ile Rezerve Boyama Teknikleri. Akademik Sosyal Araştırmalar Dergisi, Yıl, 3: 478-493.

Tezel, Z. 2009. Yazmacilik Sanatinda Desenleme Teknikleri (Kalip Tekniğiyle Ağaç Baski Uygulama Örneği). Gazi Üniversitesi Endüstriyel Sanatlar Eğitim Fakültesi Dergisi, 25: 27-40.

Trevisani, M., Cecchini, M., Siconolfi, D., Mancusi, R., Rosmini, R. 2017. Effects of beeswax coating on the oxidative stability of longripened Italian salami. Journal of Food Quality, https://doi.org/10.1155/2017/8089135

Tulloch, AP. 1971. Beeswax: structure of the esters and their component hydroxy acids and diols. Chemistry and Physics of Lipids, 6(3): 235-265.

Turna, İ., Kulaç, Ş., Güney, D., Seyis, E. (2013). Boylu maviyemiş (Vaccinium corymbosum L.)'in çelikle üretilmesinde hormon ve ortamın etkisi. Düzce Üniversitesi Ormancılık Dergisi, 9(2): 93-104.

Tomás-Barberán, FA., Ferreres, F., Tomás-Lorente, F., Ortiz, A. 1993. Flavonoids from Apis mellifera beeswax. Zeitschrift für Naturforschung C, 48(1-2): 68-72.

Winkler-Moser, JK., Anderson, J., Byars, JA., Singh, M., Hwang, HS. 2019. Evaluation of Beeswax, Candelilla Wax, Rice Bran Wax, and Sunflower Wax as Alternative Stabilizers for
Peanut Butter. Journal of the American Oil Chemists' Society, 96(11): 1235-1248.

Valdovinos-Flores, C., Alcantar-Rosales, VM., Gaspar-Ramírez, O., Saldaña-Loza, LM., Dorantes-Ugalde, J. A. 2017. Agricultural pesticide residues in honey and wax combs from Southeastern, Central and Northeastern Mexico. Journal of Apicultural Research, 56(5): 667-679.

Yilmaz, F., Dagdemir, E. 2012. The effects of beeswax coating on quality of Kashar cheese during ripening. International journal of food science \& technology, 47(12): 2582-2589.

Zhang, Y., Bi, J., Wang, S., Cao, Q., Li, Y., Zhou, J., Zhu, BW. 2019. Functional food packaging for reducing residual liquid food: thermo-resistant edible super-hydrophobic coating from coffee and beeswax. Journal of colloid and interface science, 533: 742-749.

Zhang, Y., Simpson, BK., Dumont, MJ. 2018. Effect of beeswax and carnauba wax addition on properties of gelatin films: A comparative study. Food bioscience, 26: 88-95.

Zhang, W., Lu, P., Qian, L., Xiao, H. 2014. Fabrication of superhydrophobic paper surface via wax mixture coating. Chemical Engineering Journal, 250: 431-436.

Zhao, K., Cao, XD., Zhu, SX. 2011. Effects of different concentrations of beeswax coating agent on Taiwan green jujube during storage. Storage \& Process, 4(7). 